\title{
The Response of Fruit Body Formation on Tricholoma matsutake In Situ Condition by Applying Electric Pulse Stimulator
}

\author{
Ferzana Islam and Shoji Ohga \\ Department of Agro-Environmental Sciences, Faculty of Agriculture, Kyushu University, Fukuoka 811-2415, Japan \\ Correspondence should be addressed to Shoji Ohga, ohga@forest.kyushu-u.ac.jp \\ Received 25 May 2012; Accepted 3 July 2012 \\ Academic Editors: J. A. Casaretto and N. Oraguzie
}

Copyright ( $) 2012$ F. Islam and S. Ohga. This is an open access article distributed under the Creative Commons Attribution License, which permits unrestricted use, distribution, and reproduction in any medium, provided the original work is properly cited.

\begin{abstract}
For the first time, we have demonstrated that the valuable matsutake mushroom Tricholoma matsutake production can be boosted up by using pulsed power as an electrical stimulation in the field of the natural habitat of this mushroom. After applying the electric stimulator to the specific area, the numbers of mushroom were increased more than twice. Remarkable changes were also observed by weight gaining of the fruit bodies which increased $67 \%$ in the first harvest and $69 \%$ in the second harvest, and besides length was increased by 65 to $113 \%$. From the point of view of production, our experiment shows an improvement in production which was near about double than the control. We also found that the applied electrical stimulation had some long-term effect on the second harvest and the differences of 1 st and 2nd harvest with respect to the control kept constant. These findings confirm the effectiveness of the implication of pulsed power technology for the proliferation of T. matsutake fruit body production in pine forest.
\end{abstract}

\section{Introduction}

In Japan Tricholoma matsutake is commonly known as "matsutake," this is a mushroom of coniferous woodlands and primarily occurs within the Japanese red pine Pinus densiflora Sieb.et Zucc forests [1]. In Japanese red pine forest, T. matsutake grows in well-defined areas around the $P$. densiflora host trees called "shiro" (colour of mycelia) which in Japanese means "white", "castle", or "palace". The pale colored soil around the base of the perennial host gradually gets composed of a compact mass of the hosted mycelium of $T$. matsutake. Ectomycorrhizal fungi play an important role by forming symbiotic associations with many woody species. Plants including almost all conifers usually build symbiotic relationships with soil-borne, root-colonizing, ectomycorrhizal fungi. In forest nurseries, ectomycorrhizal fungi have been introduced to improve seedling growth. Mycorrhizal phenomenon develops the absorption capabilities of the root system extending plant ability to tolerate biological and environmental stress such as phytopathogenic conditions, nutritional insufficiencies, pollution of heavy metal, extensive erosion, drought, and reduced $\mathrm{pH}[2]$. T. matsutake is an economically important ectomycorrhizal fungus in Japan where it holds its exceptional commercial value as a highly sought edible mushroom [3]. Because of being a part of Japanese culture, this mushroom is more than just a seasonal delicacy. However, the local production of this valuable mushroom has severely declined over the last few decades, and as a result Japan is also importing matsutake from other countries [4].

In the year of 1941, the annual harvest of T. matsutake in Japan showed a sharp increase which peaked around 12,000 tones, whereas in 2005 the production came down to only 34 tons [5-7]. The decline in the production is due to several factors. Among several identified reasons [8], especially those after the World War II, urban development, adoption of modern forestry practices, and aging of natural forests are the most important [9]. Besides, accumulation of humus in pine forests create a less favourable growing condition which further lowers the proliferation of the succeeding matsutake generation $[10,11]$. Apart from these confined causes, the unique mushroom host has also been facing a crisis to survive. The pine wood nematode Bursaphelenchus xylophilus has been playing a key role in deadly infesting 
the $P$. densiflora forests. These reasons interactively create conditions which disfavor the pine species and/or the fungal symbionts and ultimately reduce "matsutake" production. From the year of 1998 to 2010 in the wholesale mushroom market of Japan, in case of T. mutsutake, price showed a sharp increase from 180 to 439 US dollar. On the other hand, the market prices of other mushrooms were below 12 US dollar [12]. Hence, enhancement of local production of T. matsutake should be welcomed. The result of increase in production with our experiment can meet a large portion of the domestic demand of the country.

While focusing on "matsutake" cultivation, the natural habitat cannot be taken out of account because nearly a century of research attempts to establish synthetic "matsutake" cultivation on a large scale production basis, still remained under scientific investigation. Thus, emphasizing on the natural cultivation system to boost up the production in situ requires attention. Expansion of utilizing electric power has been focused on different agricultural crops, particularly in horticultural areas in Japan. Cultivation technologies were improved by applying electrical stimulation on green house crops such as tomato, lettuce, strawberry, and various flowers. In this aspect, promising results have been reported from research with electrical stimulator technology. Controlled experiments conducted to improve mushroom cultivation at culture research centers since 1950s signify the success of this technology. Recently, electrical sources like high voltage waves or pulses are being used for the improvement of mushroom culture [13-19]. The production of mushrooms like buna-shimeji (Hypsizygus marmoreus), eryngii (Pleurotus eryngii), and shiitake (Lentinula edodes) has been remarkably promoted with the application of electrical stimulator or pulsed power [16]. Hence, we hypothesize that applying pulse stimulation around the base of the trees in the naturally occurring T. matsutake areas of pine forests is a way to overcome the pitfall of the "matsutake" production. In our research, we considered only the specific area of pine forest which is restricted by the "matsutake" growers for the production of this specific mushroom.

\section{Materials and Methods}

2.1. Study Area. This study was conducted at Uda city, Nara prefecture pine forests on the western part of Japan having central coordinates $34^{\circ} 35^{\prime} \mathrm{N}$ and $136^{\circ} 2^{\prime} \mathrm{E}$. As the forest area of $T$. matsutake habitat belongs to private property, the production area is highly restricted. For the purpose of the study, a total of $36 \mathrm{~m}^{2}$ land was rented from the owner and exclusive permission was obtained to enter the cultivation premise. The confined area of the pine forest is at an altitude between 350 and $470 \mathrm{~m}$ above sea level. Mean annual air temperature for the last 10 years has been $13.0^{\circ} \mathrm{C}$ and precipitation $3,373 \mathrm{~mm}$. The soil $\mathrm{pH}$ ranges from 5.0 to 6.0 outside the (shiro) mycelium while inside the range was from 4.5 to 5.5 during fruit body observation period. The vegetation is dominated by 40 - to 60 -year-old naturally regenerated $P$. densiflora. The forest is characterized by eroded soil developed from volcanic lava consisting of mainly granite and a variety of parent materials as well.

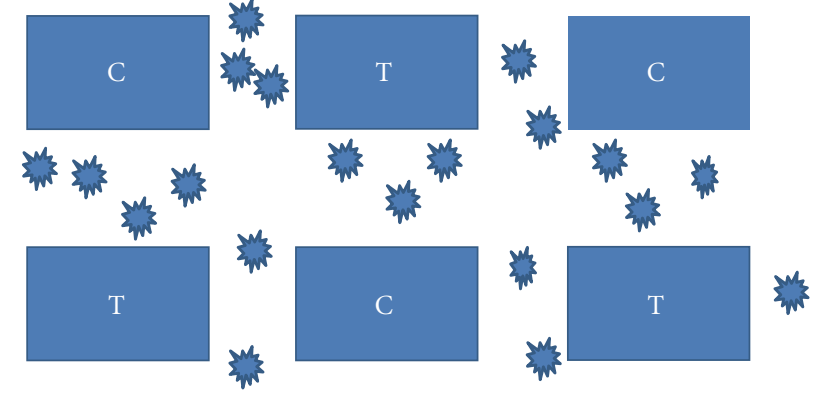

C-control plot

T-treatment plot

Pinus densiflora

Figure 1: The layout of the experimental setup. Electrical stimulation was applied to the plots defined as $\mathrm{T}$, and the plots defining with $\mathrm{C}$ are the control plots with no electric stimulation.

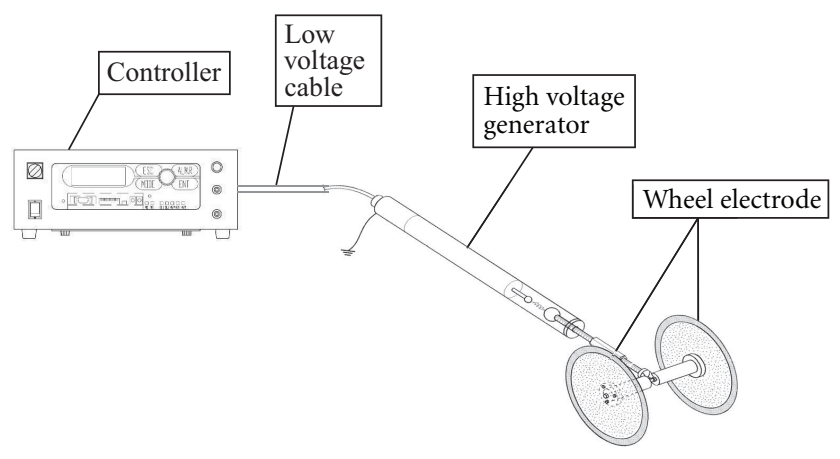

FIgURE 2: Schematic drawing of the Small Population Lightening Generator (SPLG), showing different parts of the apparatus.

Scattered patches of bare soil are not uncommon. Sandy loam texture and land topography contributes to the well drained nature of these soils. Generally, the soils are poor in fertility and acidic in reaction. Often a covering of mosses and litter layer having a thickness between 0.5 and $10 \mathrm{~cm}$ is found. To know the effect of pulse stimulation on the production of T. matsutake, the experiment was carried out during late September and until the middle of October, 2011. Figure 1 shows the layout of the experimental setup. Electric pulse stimulation was applied to three selected areas having a measurement of the plots $3 \times 2 \mathrm{~m}$ which were surrounded by three to four $P$. densiflora trees. Control plots were also included in the experiment and they were located in opposite sides (Figure 1).

\subsection{Electrical Stimulator. A pulse power generator was built} in the year of 2001 using Pulse Forming Network [17]. The device prototype was tested in a series of experiments in the mushroom factory before designing the automatic stimulator [17]. During the year of 2011, "Yushin Electrical Technology," Toyota Company, made some modifications on the electrical stimulator generator to allow portability and mobility and was named as small population lightning generator (SPLG) (Figure 2). 


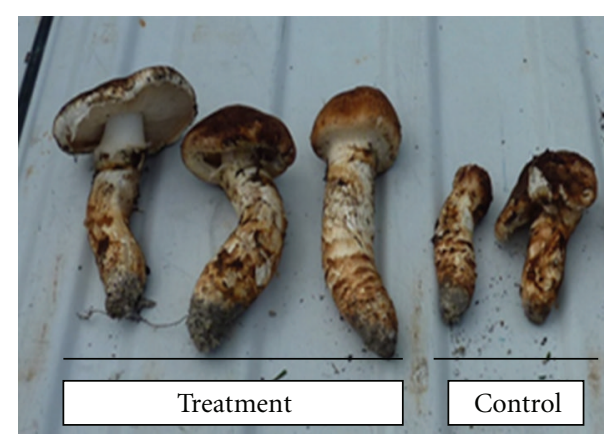

FIgure 3: Collection of some harvested Tricholoma matsutake mushroom's fruit body from both control (C) and treatment plots (T).

The SPLG consists of four parts: a controller, connection cable, a high voltage generator, and a wheel electrode. The system is powered by rechargeable AA sized batteries. Lightening is generated by an epoch-making device which can be disassembled and used elsewhere. The specifications of SPLG were as follows: the output power of the apparatus was DC0 to $100 \mathrm{kV}$, optimal value was $80 \mathrm{kv}$, the input power was DC24v, and 20AA batteries were used. Dimensions of the controller were w248, h88, and d200. HV generator dimensions were $\varphi 45 \mathrm{~L} 900$. The weight of the controller and $\mathrm{HV}$ generator was $2.6 \mathrm{~kg}$ and $2.3 \mathrm{~kg}$, respectively. The device is pushed manually by the handle while the rotating wheels of electrodes support its mobility, making it highly efficient in area coverage.

2.3. Application of Electric Stimulation Treatment. Electric pulse stimulation was applied through the electrode wheels driven along the ground. It was applied on the ground in form of lightning, and it was a constant application. The pulse application was applied for one time. A high pulse voltage of $50 \mathrm{kV}$ was applied to three different treatment plots of T. matsutake, which were selected randomly. During application, a systematic distance of $0.10 \mathrm{~m}$ was maintained between parallel walking transects which virtually allowed an entire coverage of the plots.

2.4. Mycorrhizal Fruit Body Observation. Formation of fruit body of T. matsutake usually takes place from the period of early September to the end of October. The formation of fruit bodies in our study was recorded during the fruiting season, two weeks after electric stimulation treatment. During the study period, monthly mean temperatures varied between $9^{\circ}$ and $16^{\circ} \mathrm{C}$, and precipitation was about $100 \mathrm{~mm}$ around the experimental site.

A random sampling scheme was followed to measure the weight, and length of freshly harvested mushrooms (Figure 3). Fruit bodies were recorded and collected in 6 plots during first observation and the second flushing, which were two weeks and three weeks after electric pulse stimulation, respectively.

The number of fruit bodies, weight of fruit bodies and their individual length were recorded in situ using the whole

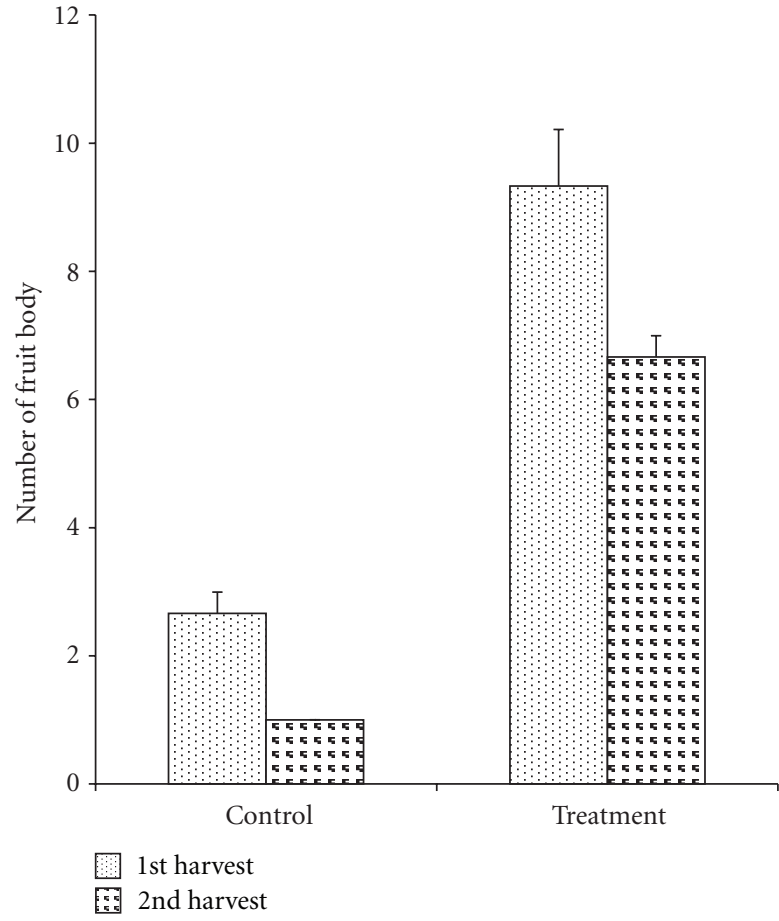

FIGURE 4: Effect of electrical stimulation on mean number of fruit body. The level of significance was analyzed by ANOVA with pair $t$-test. Data are expressed as mean \pm S.E.M. ( $n=3$ per group). Asterisk indicates significant differences $\left({ }^{*} P<0.05\right)$ from the control.

plot technique. After that, the production of T. matsutake was calculated per meter square basis.

Data were statistically analyzed, and their mean differences were evaluated with Students $t$-test using the SPSS statistical software package (v. 15.0; SPSS Inc., Chicago, IL, USA).

\section{Results}

3.1. Number of Fruit Body. Fruit body of T. matsutake was identified and collected from the plots (Figure 1). In all, 59 fruit bodies were collected at two harvesting times during fruiting season. Approximately mean number of fruit bodies in 6 plots was 9 and 7 from treatment plots, and 3 and 1 from the control plots were observed and they were harvested during first and second flushing, respectively. Number of fruit body formation was affected by the electrical stimulation and was obviously larger than the control ones (Figure 4).

3.2. Weight of Fruit Body. Mean weight of (per one) fruit body varied between $117 \mathrm{~g}$ and $120 \mathrm{~g}$ in electric pulse stimulated plots and between $70 \mathrm{~g}$ and $71 \mathrm{~g}$ from control plots during the 1st harvest and 2nd harvest, respectively. The application of electrical stimulation demonstrates a significant role in weight of fruit body. The fruit bodies of treatment plots were $67 \%$ heavier than those from the control plots in the first harvest. In the second harvest, fruit 


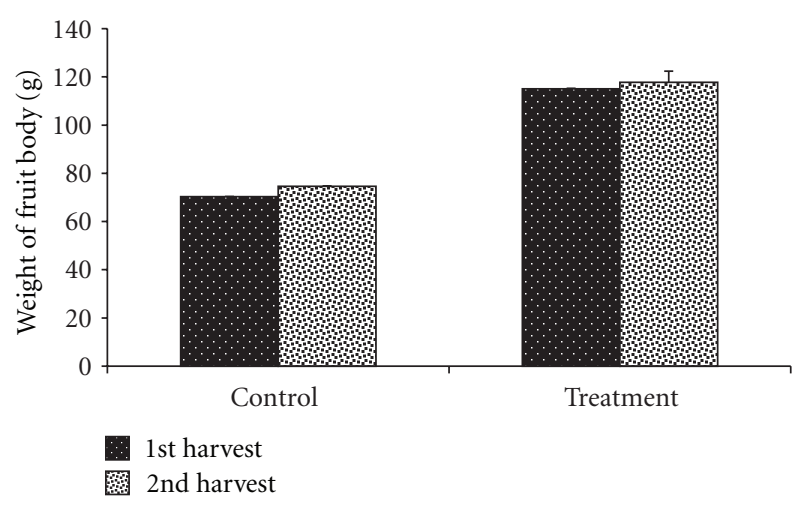

Figure 5: Effect of electrical stimulation on mean weight of fruit body. The level of significance was analyzed by ANOVA with pair $t$-test. Data are expressed as mean \pm S.E.M. ( $n=3$ per group). Asterisk indicates significant differences $\left({ }^{* *} P<0.01\right.$; $\left.{ }^{* * *} P<0.001\right)$ from the control.

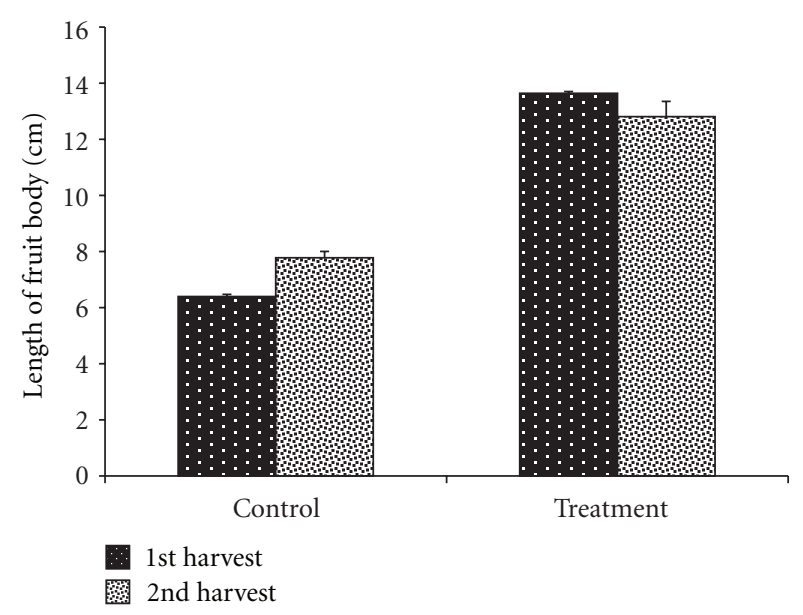

Figure 6: Effect of electrical stimulation on mean length of fruit body. The level of significance was analyzed by ANOVA with pair $t$-test. Data are expressed as mean \pm S.E.M. $(n=3$ per group $)$. Asterisk indicates significant differences $\left({ }^{* *} P<0.01\right.$; $\left.{ }^{* * *} P<0.001\right)$ from the control.

bodies were $69 \%$ heavier than those from the control plots. The experiment shows (Figure 5) highly significant effect on the mean fresh weight ( $\mathrm{g}$ ) of the fruit bodies of T. mutsutake. Significant differences were observed among the weight (g) of sporocarp of experimental plots and control ones.

3.3. Length of Fruit Body. During the 1st and 2nd harvest, mean length of (per one) fruit body varied between $13.7 \mathrm{~cm}$ and $12.8 \mathrm{~cm}$ in electrical stimulated plots and between $6.4 \mathrm{~cm}$ and $7.8 \mathrm{~cm}$ in control plots, respectively. Length of fruit bodies in treated plots was significantly higher than that of control plots (Figure 6).

3.4. Production of T. matsutake. Our experiment showed significant differences (Figure 7) on the production of $T$. matsutake comparing treated and control plots. The mean production from the treatment plots were approximately

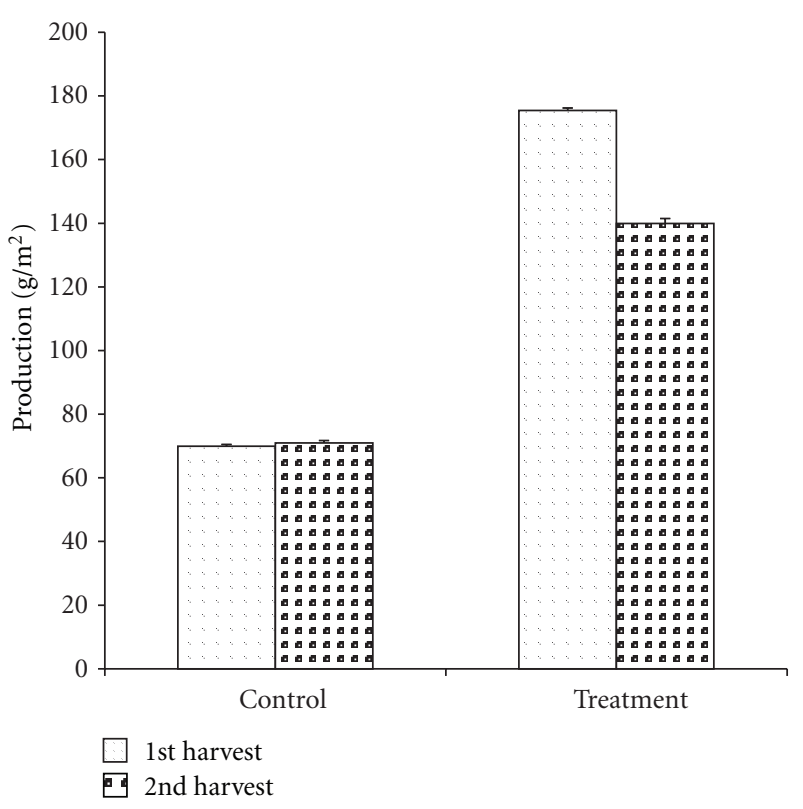

FIGURE 7: Effect of electrical stimulation on mean production of Tricholoma matsutake. The level of significance was analyzed by ANOVA with pair $t$-test. Data are expressed as mean \pm S.E.M. $(n=$ 3 per group). Asterisk indicates significant differences $(* * P<0.01$; $\left.{ }^{* * *} P<0.001\right)$ from control.

$175.5 \mathrm{~g} / \mathrm{m}^{2}$ to $140 \mathrm{~g} / \mathrm{m}^{2}$ in the first and second harvest, respectively. Mean production of T. mutsutake from the electric stimulated plots was near about two-times higher than those from the control plots. Differences in production between treatment and control plots were highly significant.

\section{Discussion}

Ectomycorrhizal mushrooms are very important and considered widespread components of the ecosystem including soil environment. Our study focused on the effect of electrical stimulation on the fruit body production of T. matsutake in the Japanese red pine forest. Other researchers found an increase in production of shiitake mushroom through pulsed high voltage, and the yield was twice as much as those that were not subjected to the electrical stimulus [17]. Findings from our study confirmed that sporocarp formation of $T$. matsutake was promoted by the electrical stimulation. Formation of sporocarps was higher in number and in regards of quality (weight, length) in stimulated zones. This kind of phenomenon might be a result of response of external application of electric pulse stimulation on the mycorrhizal physiology.

We found that the number of fruit body formation was higher in our experimental plots. Several plant species when they are exposed to environmental stress such as thunder storm, water deficit, low temperature, and ozone exposure can generate a significant amount of acetaldehyde and ethanol at an ambient level of even an elevated oxygen concentration [20-23] which can play an important role on mycorrhizal symbiosis. Among the mushroom farmers, it is well known (based on their experiences) that around the hit 
point of lightening, which may be of several tens of meters, the production of mushroom grows up extraordinarily, after several days from the lightning. The mushroom outbreak mechanism is not clear, but there are two possibilities that are suggested by some researchers. One of them is the cracks which are formed in mycelium hyphae from the result of lightning, because hyphae produce fruit bodies from cracks and another one is the enzyme activity $[16,17]$. This might be one of the reasons that the treatment plots produced higher number of fruit body than the control ones. Mycelia of T. matsutake responded to the application of electric pulse stimulator to stimulate the fruiting process. This might also a response of the electric pulse stimulation on ectomycorrhizal physiology in the fine roots.

We also observed the positive effect of electric stimulation on the quality, in scene of weight improvement, and an increase of length of the fruit body. Hones et al. [20], Adey [21], and Kerns et al. [22] have demonstrated evidences that cell functions can be changed in a variety of ways by an extremely low-frequency electric and a low-intensity magnetic field. Ohga and Iida [17] stated that electric pulse stimulation increase some of the chemical levels in ectomycorrhizal. These circumstances might play an important role to activate the cell division much higher in the mycelium structure, which helped to increase the weight and length of fruit bodies than the nonstimulated ones. This circumstance might be a reason that the quality of T. matsutake on the treated plots was superior to the control.

We analyzed the effect of electric pulse stimulation on the fruit body production per meter square basis in Japanese red pine forest. Ectomycorrhizal fungi T. matsutake showed abundant production of fruit body. The distribution of fruit body production was definitely affected by the electric pulse stimulation. The development of fruiting bodies might be the result derived from some specific activation at the enzyme level after the application of pulse electricity. As far as we know, fungi of ascomycetous and terrestrial phycomycete have been studied and described for only tropic behaviors, that is, negative tropisms which is involved in the spacing of hyphae during the development of mycelia and the associated tropisms with the fusion of heterothallic hyphae at the time of formation of sexual structures [23, 24]. McGillivray and Gow [24] and Robinson [25] suggested that different fungus shows different behavior when they are stimulated through applied electric field: germ tube formation and branching, hyphal extension direction, branching frequency, and germination all could be affected. These reasons might play an important role on the higher production of T. matsutake.

Mushroom yield was observed for both on first flush and on second flush. Yield from the first harvest was superior to the second harvest, but both of them had higher production than the controls. As expected, mushroom fruit body formation was positively correlated with mycelial growth and maturity. Fruit body formation was lower for the second flush; this phenomenon might be explained by the larger fruiting on the first flush. There could be a long term response of the stimulation to mycorrhizal physiology in the fine roots. According to Gooday [23], fusion of heterothallic hyphae during the formation of sexual structure is associated with the tropisms. This might be a positive response of electrical stimulation to enhance the development of fruit body. There was a considerable lag time in the response of the above-ground fruit body production compared to the belowground ectomycorrhiza production. This lag time might partly be explained by the role of fruit body production in producing macrofungi below ground.

Exogenous electrical field might play a role when the mycelia are exposed to it. The mechanism of electrical stimulation effects was not studied. Hence, it is hard to make generalization. From the point of ecological view, one of the most important groups in forest systems is those fungi that form ectomycorrhizae, essential interfaces between soil and trees. The promotion of fruit body production mechanisms of T. matsutake in Japanese red pine forest was significantly enhanced by electric pulse stimulation. Probably it is the result caused by a specific stimulation on the formation of primordium. It is really difficult to determine whether there are any of the mechanisms which were operating in the ectomycorrhizal physiology from our research, because only fruit body numbers, weight and length were studied.

Fruit body formation of T. matsutake was undoubtedly promoted by the application of electric pulse stimulation. In the mycorrhizal association, electric pulse stimulation has its own potentiality. Ectomycorrhizal fungi have been well recognized for improving stand growth in forest. From the point of ecology, in forest system one of the most important groups are those fungi from ectomycorrhizae, essential interfaces between soil and trees. Dynamics models of the ectomycorrhizal association are important not only from the view of understanding of mycorrhizal interactions but also from the standpoint of forest practices.

\section{Conclusion}

In this paper, we bring evidence that the technology of pulse power stimulation can successfully increase the quality as well as quantity for the production of T. matsutake. Our study showed that electric stimulation also had some long term effect on the second flushing. As the fruit body formation of $T$. matsutake under artificial condition did not show any significant result till now, our present study has been made in developing methods to maximize production in forests where it occurs naturally. Techniques based on pulse stimulation on natural T. matsutake occurring sites can have a bright future for the research work on this mushroom. As the mechanism of fruit body formation is not still fully understood, it needs further more research work. Because of this study which was limited to one habitat type, making extension of the results, we hope to do further more studies on T. matsutake, in different red pine forest habitats in Japan, including host interaction and their biological and physiological changes.

\section{Acknowledgments}

These studies were supported by Kyoeisya Chemical Co. Ltd., Nara 630-8453, Japan, and Yushin Electric Technology Co. Ltd., Toyota 471-0855, Japan. 


\section{References}

[1] T. Ito, Mushroom, Edited by M. Ogawa, K. Kinugawa, Handbook, Asakura, Japan, 2000.

[2] S. Smith and D. J. Read, Mycorrhizal Symbiosis, vol. 640, Academic Press, London, UK, 1996.

[3] I. R. Hall, W. Yun, and A. Amicucci, "Cultivation of edible ectomycorrhizal mushrooms," Trends in Biotechnology, vol. 21, no. 10, pp. 433-438, 2003.

[4] W. Yun, I. R. Hall, and L. A. Evans, "Ectomycorrhizal fungi with edible fruiting bodies 1 . Tricholoma matsutake and related fungi," Economic Botany, vol. 51, no. 3, pp. 311-327, 1997.

[5] M. Ogawa, How to Produce Matsutake Mushroom, Matsutake Research and Consultation Office, Forest Service Research Station, Nara, Japan, 1982.

[6] A. Yamada, "To the artificial cultivation: the present situation and the approach on the developmental research," Technology and Innovation, vol. 15, pp. 24-28, 2005 (Japanese).

[7] N. Kinoko, Plants World, Tokyo, Japan, 2008.

[8] M. Ogawa, "Ecology of Tricholoma matsutake (Ito et Imai) Sing, mycorrhizal fungus, in pine forest," in Proceeding of the 9th International Scientific Congress on the Cultivation of Edible Fungi,, K. Mori, Ed., pp. 733-744, Mushroom Science IX (1), Tokyo, Japan, 1974.

[9] M. Ogawa, "Microbial ecology of mycorrhizal fungus, Tricholoma matsutake (Ito et Imai) Sing. In pine forest. II. Mycorrhiza formed by Tricholoma matsutake," Bulletin of the Government Forest Experiment Station, vol. 278, pp. 21-50, 1975.

[10] W. Yun, I. R. Hall, and L. A. Evans, "Ectomycorrhizal fungi with edible fruiting bodies 1 . Tricholoma matsutake and related fungi," Economic Botany, vol. 51, no. 3, pp. 311-327, 1997.

[11] K. Futai, Matsu-Gare ha Mori no Kansen-Sho, Bunichi, Tokyo, 2003.

[12] Ministry of Agriculture, Forestry and Fisheries of Japan, 2011.

[13] S. Takahashi, K. Mitobe, T. Suzuki, and N. Yoshimura, "Growth control of Shiitake hyphae due to electric shock," in Proceeding of the Institute of Electrostatics, pp. 53-54, Tokyo, Japan, 1990.

[14] K. Kudo, K. Mitobe, and N. Yoshimura, "Electrical stimulated multiplication of Lentinulus edodes," Journal of the Institute of Electrostatics Japan, vol. 23, no. 4, pp. 186-190, 1999 (Japanese).

[15] K. Mitobe, K. Kudo, and N. Yoshimura, "Improvement production of fruit-body of Lentinulus edodes by Electrical Stimulation in Artificial Bed-Blocks," Journal of the Institute of Electrostatics Japan, vol. 25, no. 3, pp. 149-152, 2001 (Japanese).

[16] S. Ohga, S. Iida, C. D. Koo, and N. S. Cho, "Effect of electric impulse on fruit body production of Lentinulus edodes in the sawdust- based substrate," Journal of the Japanese Society of Mushroom Science and Biotechnology, vol. 9, no. 1, pp. 7-12, 2001.

[17] S. Ohga and S. Iida, "Effect of electric impulse on sporocarp formation of ectomycorrhizal fungus Laccaria laccata in Japanese red pine plantation," Journal of Forest Research, vol. 6, no. 1, pp. 37-41, 2001.

[18] S. Tsukamoto, T. Maeda, M. Ikeda, and H. Akiyama, "Application of pulsed power to mushroom culturing," in Proceedings of the 14th IEEE International Pulsed Power Conference, pp. 1116-1119, Dallas, Tex, USA, June 2003.
[19] S. Tsukamoto, H. Kudoh, S. Ohga, K. Yamamoto, and H. Akiyama, "Development of an automatic electrical stimulator for mushroom sawdust bottle," in Proceeding of the 15th Pulsed Power Conference, pp. 1437-1440, Monterey, Calif, USA, June 2005.

[20] I. Hones, A. Pospischil, and H. Berg, "Electrostimulation of proliferation of the denitrifying bacterium Pseudomonas stutzeri," Bioelectrochemistry and Bioenergetics, vol. 44, no. 2, pp. 275-277, 1998.

[21] W. R. Adey, "Collective properties of cell membranes," in Interaction Mechanisms of Iow-Level Electriomagnetic Fields in Living Systems, B. Norden and C. Ramel, Eds., pp. 47-77, Oxford University Press, Oxford, UK, 1992.

[22] G. Kerns, E. Bauer, and H. Berg, "Electrostimulation of cellulase fermentation by pulsatile electromagnetically induced currents," Bioelectrochemistry and Bioenergetics, vol. 32, no. 1, pp. 89-94, 1993.

[23] G. W. Gooday, "Chemotaxis and chemotropism in fungi and algae," in Premitive Sensory and Communication Systems, M. J. Carlile, Ed., pp. 155-204, Academic Press, London, UK, 1975.

[24] A. M. McGillivray and N. A. R. Gow, "Applied electrical fields polarize the growth of mycelial fungi," Journal of General Microbiology, vol. 132, no. 9, pp. 2515-2525, 1986.

[25] K. R. Robinson, "The responses of cells to electrical fields: a review," Journal of Cell Biology, vol. 101, no. 6, pp. 2023-2027, 1985. 


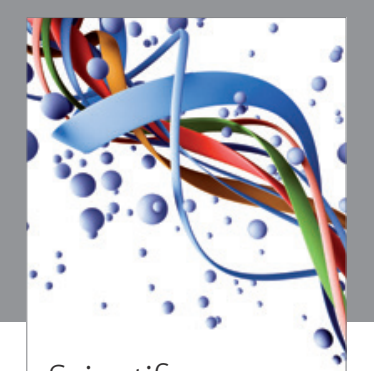

Scientifica
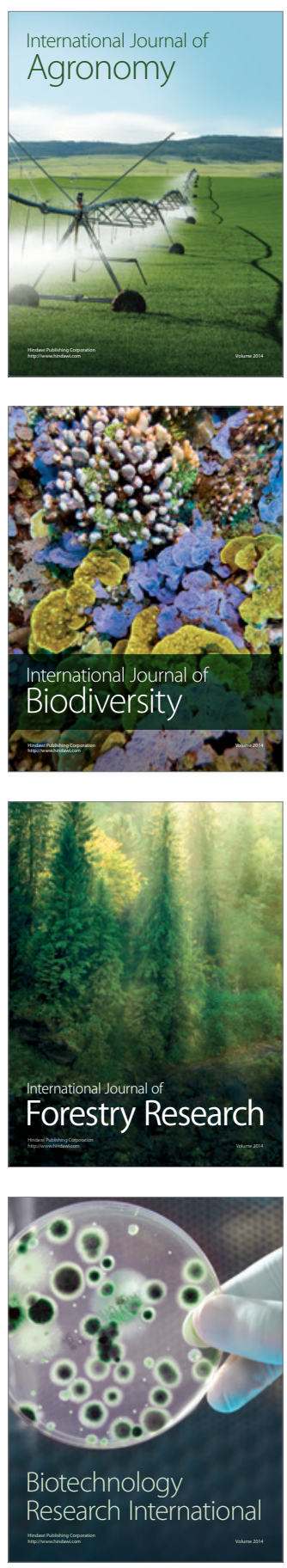
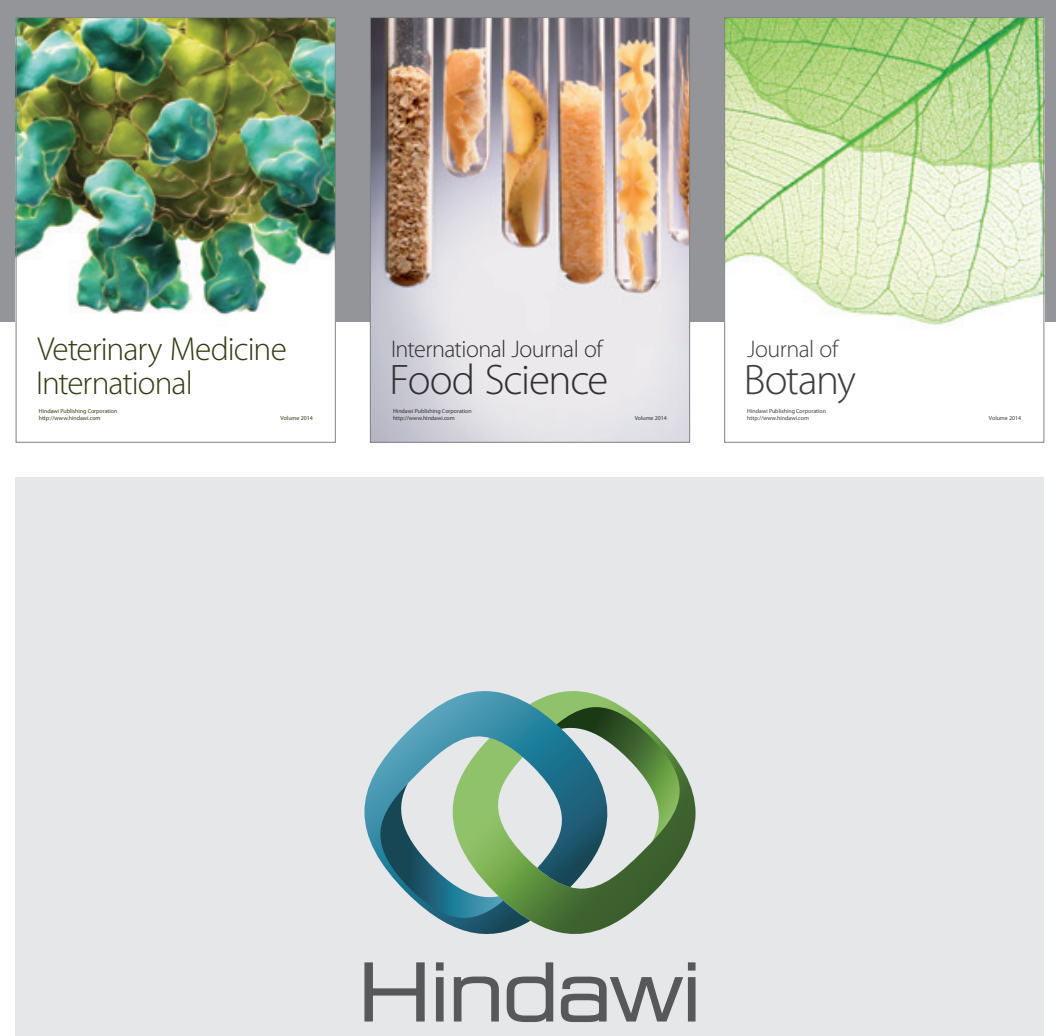

Submit your manuscripts at

http://www.hindawi.com
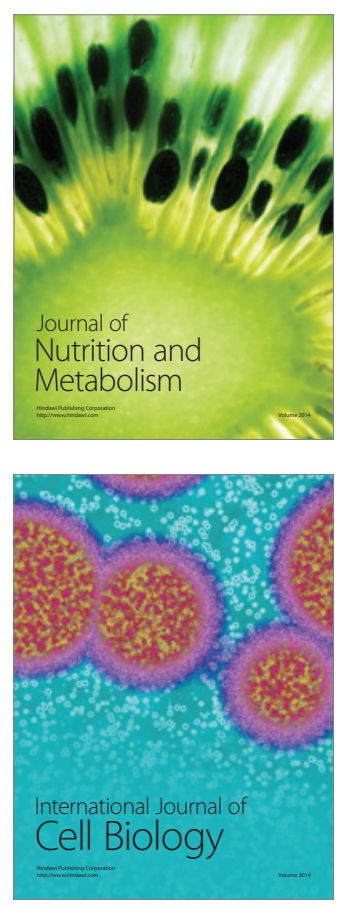
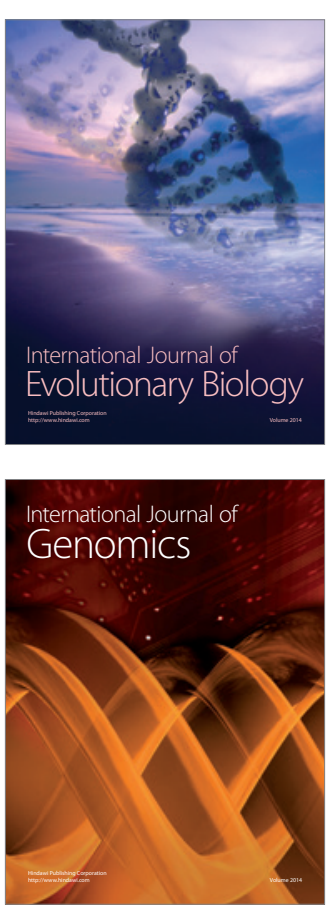
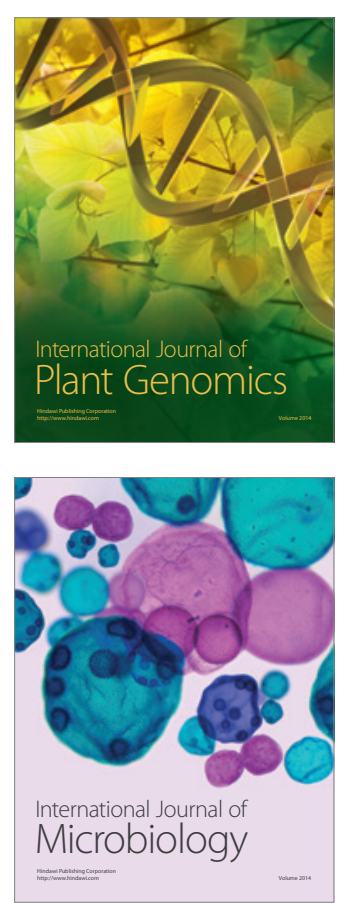

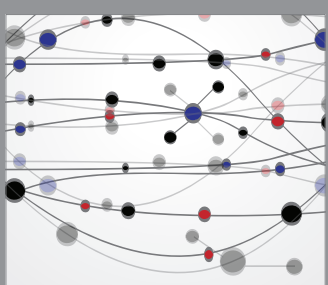

The Scientific World Journal
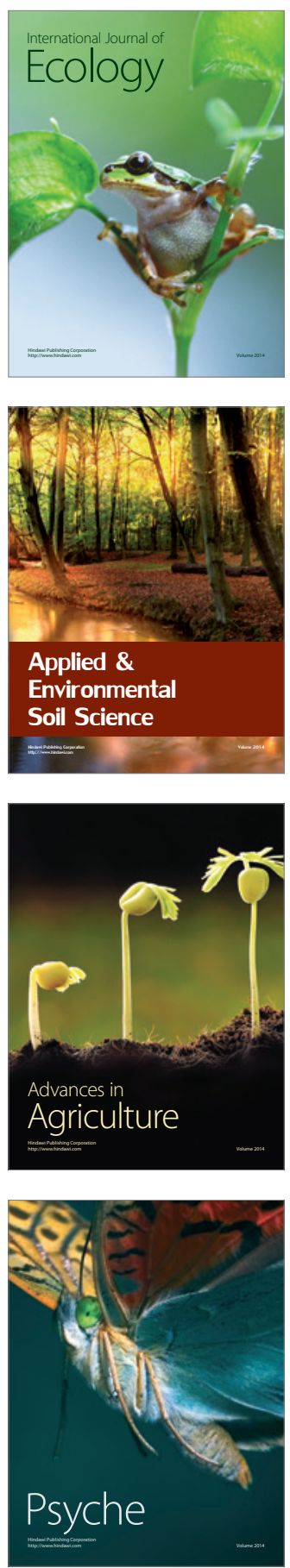